IZA DP No. 6299

\title{
Exploring the Causes of Frictional Wage Dispersion
}

Volker Tjaden

Felix Wellschmied

January 2012 


\title{
Exploring the Causes of Frictional Wage Dispersion
}

\author{
Volker Tjaden \\ Bonn Graduate School of Economics \\ Felix Wellschmied \\ Bonn Graduate School of Economics \\ and IZA
}

Discussion Paper No. 6299
January 2012

IZA

P.O. Box 7240

53072 Bonn

Germany

Phone: +49-228-3894-0

Fax: +49-228-3894-180

E-mail: iza@iza.org

\begin{abstract}
Any opinions expressed here are those of the author(s) and not those of IZA. Research published in this series may include views on policy, but the institute itself takes no institutional policy positions.

The Institute for the Study of Labor (IZA) in Bonn is a local and virtual international research center and a place of communication between science, politics and business. IZA is an independent nonprofit organization supported by Deutsche Post Foundation. The center is associated with the University of Bonn and offers a stimulating research environment through its international network, workshops and conferences, data service, project support, research visits and doctoral program. IZA engages in (i) original and internationally competitive research in all fields of labor economics, (ii) development of policy concepts, and (iii) dissemination of research results and concepts to the interested public.
\end{abstract}

IZA Discussion Papers often represent preliminary work and are circulated to encourage discussion. Citation of such a paper should account for its provisional character. A revised version may be available directly from the author. 


\section{ABSTRACT}

\section{Exploring the Causes of Frictional Wage Dispersion*}

Standard search models are unreliable for structural inference of the underlying sources of wage inequality because they are inconsistent with observed residual wage dispersion. We address this issue by modeling skill development and duration dependence in unemployment benefits in a random on the job search model featuring two-sided heterogeneity. General human capital and search on the job are the main drivers behind our model's empirical success in replicating wage dispersion (residual and overall). A realistic quantitative appraisal of search efficiencies needs to account for one third of job to job transitions resulting in wage losses. Controlling for them has important implications for the inferred sources of wage inequality. We find that the search friction accounts for around 18 percent of observed wage inequality.

JEL Classification: J24, J31, J64

Keywords: frictional wage dispersion, search model, heterogeneity

Corresponding author:

Felix Wellschmied

Bonn Graduate School of Economics

Department of Economics

University of Bonn

Kaiserstraße 1

53113 Bonn

Germany

E-mail: s3fewell@uni-bonn.de

\footnotetext{
* An earlier version of this paper was entitled "Why do the Unemployed Spend so Little Time Searching?" We thank Marcus Hagedorn for a very helpful discussion and are grateful for comments from Christian Bayer, Alexander Bick, Jörg Breitung, Wouter Den Haan, Thomas Hintermaier, Alexander Kriwoluzky, Dirk Krüger, Moritz Kuhn, lourii Manovskii, Monika Merz, Konstantinos Tatsiramos, and Gianluca Violante. We also thank seminar participants in Bonn and at the University of Pennsylvania and conference participants at the 2011 meeting of the Verein für Socialpolitik, the 4th IAB PhD workshop: Perspectives on (Un-)Employment, and the 8th ECC/CEPR, IfW Labour Market Workshop: Wages in a Time of Adjustment and Restructuring. Both authors gratefully acknowledge support from the Deutsche Forschungsgemeinschaft (DFG) through the Bonn Graduate School of Economics. Mr Tjaden also gratefully acknowledges a Fulbright grant and thanks the Department of Economics at the University of Pennsylvania for its hospitality.
} 


\section{Introduction}

For any equilibrium analysis pertaining to wage inequality, knowledge of the wage offer distribution and the distribution of idiosyncratic wage uncertainty are of first order importance. If, for example, the wage offer distribution is very disperse, impediments to efficient search entail much larger welfare losses than otherwise. Yet, their empirical inference has proven to be non-trivial. They are inherently unobservable and observed wage dynamics are the result of people self-selecting into and out of employment and accepting and refusing wage offers while on the job. Reduced form estimations have relied on instrumental variable approaches, but credible instruments have proven hard to come by. Alternatively, one can make structural assumptions to infer the wage offer distribution from within a model environment.

The challenge for structural approaches is to correctly identify the channels that determine the range of acceptable job offers to the worker. The search friction introduces a trade-off between accepting a job-offer now or waiting in unemployment to sample a better one. This induces what in our paper is referred to as frictional wage dispersion: workers of identical observable characteristics earn different wages in equilibrium. In fact, given that the typical Mincer wage regression explains only around a third of observed wage variation leaving substantial residual wage dispersion it is potentially a quite important driver of wage inequality.

Yet, as Hornstein et al. (2011) (henceforth HKV) point out in a recent contribution, a large part of the search and matching models commonly used in empirical applications have a hard time generating anywhere near as much residual inequality as is commonly found in U.S. data. One could conclude from this finding that most residual inequality is the result of measurement error in wages or the explanatory variables. It could, however, also mean that structural estimations of search models are missing important channels shaping the workers' employment decisions. Indeed, estimated versions of many of the models presented in HKV either have to attribute much of wage inequality to measurement error or produce unreasonably low estimates of discount factors and/or the replacement rate in order to accommodate the large amount of wage dispersion. 
Our main contribution is twofold. First, we build a structural model that is consistent with the large amount of residual wage dispersion present in our data set. Our model includes a number of important channels that enlarge the set of acceptable job offers: learning and search on the job, skill depreciation in unemployment and finite duration of unemployment benefits. We demonstrate that the skill development process and the ability to search on the job are key ingredients in generating realistic amounts of frictional wage dispersion. We show that job to job transitions resulting in nominal wage losses are an empirically pervasive phenomenon that allows us to discriminate between our model and a pure on the job search model. Second, we demonstrate how we can use our model to structurally quantify the different sources of wage inequality using individual panel data of wage dynamics and employment choices. This allows us to measure the contribution of firm effects, changes in individual productivity and measurement error to wage dispersion across agents and over the life cycle. Across different age cohorts, our baseline specification finds a mean contribution of 17.5 percent of frictional wage dispersion to overall inequality.

We can also shed light on why the literature so far has produced such divergent results regarding the contribution of search frictions to overall wage dispersion. This has again to do with the frequent occurrence of wage losses upon employment transitions. Some studies, such as Hagedorn and Manovskii (2010) have concluded that search frictions are responsible for only 6 percent of overall wage inequality. In comparison, the seminal paper by Postel-Vinay and Robin (2002) finds numbers as high as 60 percent. Our results suggest that the way search on the job is modeled in the latter paper can be responsible for that finding. When solving a pure on the job search calibration of our model, capable of generating large frictional wage dispersion but neglecting wage losses, the contribution of the search friction to overall wage inequality more than doubles to over 40 percent. We therefore caution against calibrating on the job search models to observed employment to employment flow rates as this likely overstates the efficiency of on the job search.

Related to our paper are a few recent contributions that also augment the standard search model to replicate the empirically observed amount of residual wage dispersion. Burdett et al. (2009) and Carrillo-Tudela (2010) introduce a restricted 
form of experience into on the job search model. Papp (2011) shows that wage posting together with Betrand competition between firms for the service of workers can lead to almost arbitrarily large frictional wage dispersion. Also related is a line of literature that empirically asses the importance of different sources of wage inequality. Bontemps et al. (1999, 2000) set up on the job search models and structurally estimate them on French panel data. This line of literature also includes the aforementioned contribution by Postel-Vinay and Robin (2002). Hagedorn and Manovskii (2010) choose a reduced-form approach in quantifying the contributions of search frictions to wage inequality. Finally, Low et al. (2010) use an instrumental variable approach to estimate the firm offer distribution and idiosyncratic wage risk.

The remainder of the paper is structured as follows. In Section 2 we provide some empirical motivation and have a closer look at the efficiency of on the job search. We present our model in Section 3. Section 4 discusses parameterization. Section 5 presents and analyzes the results. Section 6 concludes. Additional information on the empirical part and the numerical algorithm is relegated to an appendix. All programs used for data analysis and model solution are available on the author's web pages.

\section{Empirical Motivation}

In this section, we introduce our data set, the Survey of Income and Program Participation (SIPP), and discuss sample selection. To motivate our further analysis, we then present two sets of facts from the data. First, we estimate residual wage dispersion and show that its magnitude is substantial and comparable to what other studies find. Second, we present wage changes after employment to employment transitions. We argue that previous studies of on the job search have inadequately addressed a large fraction of employment to employment transitions which result in wage losses. 


\subsection{Data Source and Sample Creation}

Our model to be presented in the next section places great emphasis on job-to-job transitions and accompanying wage changes as well as wage dynamics on the job. Our empirical analysis needs to accurately identify these phenomena. We therefore require longitudinal monthly wage information which identify employer and occupation changes. The data set which best meets these requirements is the 1993 sample of SIPP. SIPP is a representative sample of the non-institutionalized civilian US population maintained by the US Census Bureau. Its main goal is to track income dynamics and welfare program participation of households and individuals. The level of detail it provides in individual records allows us to accurately identify an individual's main job and hourly wages on that job. In addition, the 1993 cohort combined survey data with administrative records to accurately identify employer changes, which is why we use this particular sample.

The survey covers the years 1993-1995 (which also includes some observations from 1992 $)^{1}$ and therefore provides us with up to 36 months of observations per individual. We use observations from individuals aged 23-65 for whom we require complete information for the period of the interview on the individual's employment status, age and employer id. On top of that, we only consider an individual's primary $\mathrm{job}^{2}$. These restrictions leave us with 754,345 person/month observations.

The SIPP is a collection of panels of which a new one starts every year. In constructing the panels, the Census Bureau randomly assigns people to rotation groups which are then interviewed subsequently on a four-month basis. One completed rotation is called a wave. During the interviews, the respondents give information on their labor market status for each week in the past four months separately, which is then used to assign one of eight possible activity statuses. While this form of reporting allows for a very precise labor market classification it also constitutes one of the sample's few drawbacks. It makes it very hard to compare unemployment measures based on this classification to unemployment in the Current Population

\footnotetext{
${ }^{1}$ We use the CEPR SIPP extracts available for download at http://www.ceprdata.org/sipp/sipp_data.php.

${ }^{2}$ As primary job we consider the position where the largest share of hours worked is spent.
} 
Survey (CPS). It has also been shown to downward bias estimates of transition flows between employment and unemployment ${ }^{3}$. When calibrating these flow rates below, we therefore use estimates from corresponding CPS cohorts. Both panels are representative samples from the same population so this should be unproblematic.

\subsection{Frictional Wage Dispersion in the SIPP}

We start by estimating the amount of residual wage dispersion in our data against which to later compare the amount of frictional dispersion in our model. To control for observed and unobserved worker heterogeneity as well as time effects, we employ the estimation method outlined in Hornstein et al. (2007). For each period in the sample (unique combination of year/month) we run an OLS regression of individual log-wages on 9 regional dummies, 14 occupational dummies ${ }^{4}, 4$ education dummies (less than high school, high school, some college, college), a dummy for marital status, one for non-white, one for disabled workers, age, age squared and the number of children. This yields a set of residuals $\left\{\epsilon_{i t}\right\}$. The mean $R^{2}$ of these regressions is 0.36 . We then compute unobserved individual effects as $\bar{\epsilon}_{i}=\sum_{t=1}^{T_{i}} \epsilon_{i t} / T_{i}$. The residual wage corresponding to individual $\mathrm{i}$ in period $\mathrm{t}$ is then $\tilde{w}_{i t}=\exp \left(\epsilon_{i t}-\bar{\epsilon}_{i}\right)$.

Table 1 summarizes a number of moments of the resulting distribution of residual wage inequality: the mean to minimum ratio, the Gini coefficient and the variance of $\log$ wages. The mean-min ratio is the summary statistic advocated by HKV and for comparability to their result and other studies, it is our leading measure. Since the lowest wages in the data are likely the result of measurement error, we report a number of low percentiles as candidates for the minimum wage. The size or residual inequality is substantial and comparable to the one found by other studies.

\footnotetext{
${ }^{3}$ See Mazumder (2007) for a discussion.

${ }^{4}$ Occupation is likely to be correlated with individual ability as well firm effects. We want to control for the former but leave the latter untouched. Our compromise is to only include very broad occupational categories as they should be less firm specific. Dropping occupations from our estimations altogether lowers the $R^{2}$ by 0.1 without materially affecting the Mean-Min Ratio, our main summary statistic for residual inequality.
} 
Table 1: Residual Wage Inequality in the 1993 SIPP

\begin{tabular}{c|c|c|c|c}
\hline \multicolumn{3}{c|}{ Mean-Min Ratio } & Gini & $\operatorname{Var}\left(\log \left(\tilde{w}_{i t}\right)\right)$ \\
\hline \hline & $1^{\text {st }}$ & 2.18 & & \\
Pctl. & $5^{\text {th }}$ & 1.48 & 0.091 & 0.031 \\
& $10^{t h}$ & 1.31 & & \\
\hline
\end{tabular}

Notes: The table reports summary measures of residual wage inequality in the 1993 SIPP: the mean to minimum ratio, Gini coefficient and variance of log wages after controlling for region, broad occupation, education, marital status, non-whites, disabilities, a quadratic in age and number of children. Since the lowest wage observations in the data are likely the result of measurement error, we report several low percentiles as candidates for the actual minimum wage in the data.

\subsection{Wages and On the Job Search}

\subsubsection{Wage Losses from Employment to Employment Transitions}

One of the most important potential channels for enlarging the set of acceptable job offers to the worker is the ability to continue searching on the job. In this case, the trade-off is between earning more than unemployment benefits now and a reduced search efficiency on the job ${ }^{5}$. If search in the job is fairly efficient, this can substantially enlarge the range of acceptable offers.

Studies of on the job search typically calibrate on the job search efficiency to observed employment to employment flow rates. Meanwhile, Fallick and Fleischman (2004) find in the CPS that a worker who reports to be actively searching on the job is more likely to be unemployed next month. This seems clearly at odds with predictions of job-ladder models. Nágipal (2005) shows for the basic job ladder model that search on the job would have to be more efficient than during unemployment in order to replicate observed flow rates.

In our view, these pieces of evidence imply other mechanisms behind the magnitude of employment to employment movements than job ladders only. They also hint at on the job search being less efficient than previously assumed. In Table 2

\footnotetext{
${ }^{5}$ Of course, if search efficiency on the job is as high as in unemployment, the worker accepts any wage offer at least as high as UI benefits.
} 
we supply additional evidence to support that claim. A pervasive phenomenon in the data are job to job transitions resulting in nominal wage losses. In the whole population and across different subsamples, roughly one third of all transitions result in workers earning lower wages than on their previous jobs. If we look at real wage changes, this number increases to roughly one half ${ }^{6}$. As the table also shows, this result is not driven by any particular subsample of the population.

Table 2: Wage Cuts after EE Movement

\begin{tabular}{llrr}
\hline \hline Sample Stratification & & Share loss & Mean loss \\
\hline Whole sample & & 0.339 & -0.22 \\
\hline Year & 1993 & 0.3301 & -0.2068 \\
& 1994 & 0.3299 & -0.23 \\
& 1995 & 0.3638 & -0.2256 \\
\hline Sex & Male & 0.3367 & -0.2261 \\
& Female & 0.3421 & -0.2122 \\
\hline Age & $23-30$ & 0.3483 & -0.2274 \\
& $31-50$ & 0.3368 & -0.2198 \\
Income & $51-65$ & 0.3230 & -0.1981 \\
& Lowest 25\% & 0.2316 & -0.169 \\
& $25-75 \%$ & 0.3514 & -0.2277 \\
& Top 25\% & 0.4428 & -0.2396 \\
\hline
\end{tabular}

Notes: The Table shows the share of workers incurring a nominal wage cut after a job to job movement for the whole population and different subsamples in the 1993 SIPP. Mean loss reports the mean wage loss in log points conditional on suffering a wage cut upon movement.

In the interpretation of this paper, an important part of these transitions are either the result of jobs accepted within notice period of dismissal or movements for non-economic reasons (moving in with one's spouse, moving close to ones parents, etc.). To proxy for these causes, our model includes what Jolivet et al. (2006) label forced job movements: randomly drawn on the job offers which the worker can accept or move into unemployment. If idiosyncratic worker productivity uncertainty is large relative to firm dispersion, parts of these wage cuts are the result of negative

\footnotetext{
${ }^{6}$ In principle, the worker should only care about real wages. But in the presence of some wage rigidity the worker expects a wage loss on his current job as well and compares nominal wages.
} 
shocks to general human capital and some of them are simply measurement error ${ }^{7}$. Our baseline model therefore includes innovations to worker productivity and all our simulations explicitly include measurement error to account for these causes. Appendix C contains further discussions on our empirical treatment of job to job movements.

\subsubsection{Alternative Explanations}

Before moving on to present the model, we briefly want to discuss an alternative explanation for those wage losses proposed by Postel-Vinay and Robin (2002). They lay out a model where wages can only be renegotiated by mutual agreement and the firm has all the bargaining power. Wage raises on the job occur as a result of counteroffers to bids by other firms. They demonstrate that in such a framework workers may accept wage cuts upon job to job transitions, if the option value of working at the other firm is sufficiently high. Workers only move to firms more productive than their current employer and very productive firms offer the potential of large future wage gains.

A testable implication of these types of models is that expected future wage growth with the new employer should be an increasing function of the wage cut accepted. Figure I plots cumulative wage growth with the new job against the initial wage change for our population of job to job transitions. There is no relationship between the initial wage change and consecutive wage growth. In Figure II we restrict the sample to agents whom we observe for at least two years with their new job (This time, the initial wage cut is included in the sum). We again find no evidence, that agents that accepted an initial wage cut are compensated by steeper wage profiles on the new job ${ }^{8}$. Hagedorn and Manovskii (2010) provide further evidence against the

\footnotetext{
${ }^{7}$ As a robustness test, we also constructed three-months-averages of wages after a movement to mitigate other sources of reporting error in the following the transition. This did not affect our estimates.

${ }^{8}$ Two caveats in interpreting this finding should be mentioned. First, it is of course possible that the higher expected wage increases lie further in the future than the two years we observe. Given that Dustmann and Meghir (2005) find wage-tenure profiles to be basically flat after two years, however, we find this not very likely. Secondly, there is a possibility that a part of these wage losses
} 
mechanism. They show that wage growth of job stayers in the US is uncorrelated to local labor market tightness whereas the model by Postel-Vinay and Robin (2002) would predict it to be an increasing function of the probability to receive a job offer ${ }^{9}$.

Figure I:

Initial Wage Change and Subsequent Wage Growth I

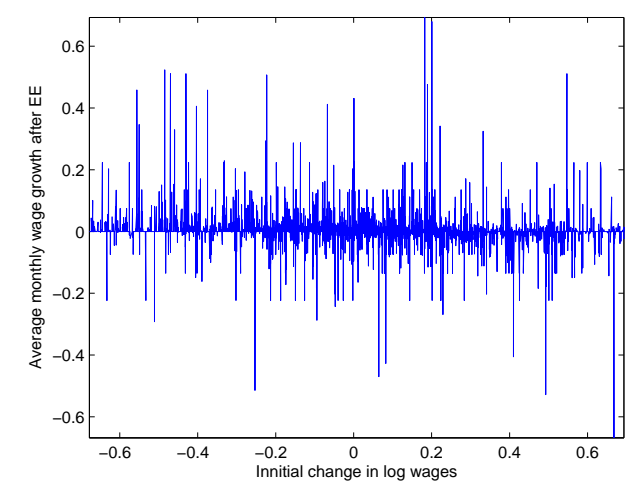

Notes: This figure was generated using all observed

EE movements. The horizontal axis reports initial

wage change upon movement and the vertical axis cumulative wage growth in the two years after, excluding the initial wage change.
Figure II:

Initial Wage Change and Subsequent Wage Growth II

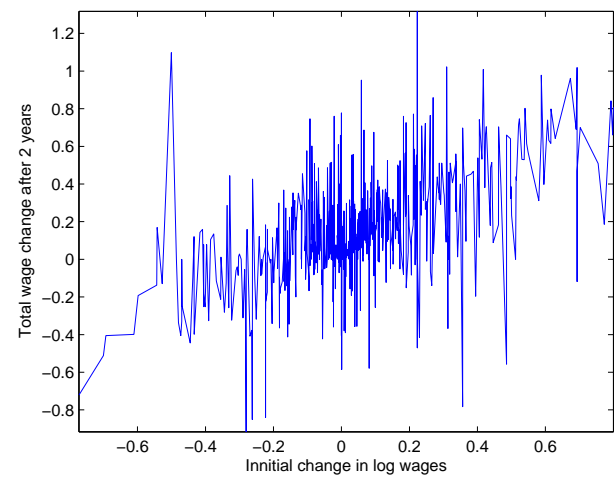

Notes: This figure was generated using only EE movements where the worker was subsequently observed for at least 24 months. The horizontal axis reports initial wage change upon movement and the vertical axis cumulative wage growth in the two years after.

are compensated in the form of benefits like health insurance coverage. Given the the limitations of our current data set, we cannot rule out this effect and leave its quantification to future research.

${ }^{9}$ The same holds true for models that stress the importance of learning about match quality over time. 


\section{The Model}

\subsection{The Labor Market}

A firm is a match producing with the worker's idiosyncratic log productivity $A_{t}$ and firm specific log productivity $\Gamma_{t}{ }^{10}$. We assume that search is random and the labor market is governed by a matching function $m=\xi u^{\iota} v^{1-\iota}$ where $v$ are vacancies and $u$ is unemployment. As usually, an unemployed worker contact rate $q(\theta)$ and a job offer probability $p(\theta)$ can be derived from that matching function. Let $\chi\left(A_{t}, \Gamma_{t}, \phi_{t}\right)$ and $\psi\left(A_{t}, \phi_{t}, \varpi\right)$ be measures of employed and unemployed agents over idiosyncratic productivity, firm specific productivity, the life cycle state $(\phi)$ and an indicator for unemployment benefit entitlement $\varpi$ in period $t$. Firm log productivity is drawn from the distribution $F \sim N\left(0, \sigma_{F}^{2}\right)$. Once a match is formed it produces output $y_{t}$ according to

$$
y_{t}=\exp \left(A_{t}+\Gamma_{t}\right)
$$

\subsection{The Household Problem}

Household period income is given by:

$$
I_{t}\left(A_{t}, \Gamma_{t}, \phi_{t}\right)= \begin{cases}w_{t}\left(A_{t}, \Gamma_{t}, \phi_{t}\right) & \text { if employed } \\ \min \left\{b_{\max }, b_{t}\left(A_{t}, \phi_{t}\right)\right\}+Z\left(A_{t}, \phi_{t}\right) & \text { if } \varpi=u_{1} \\ \left.Z_{t}\left(A_{t}, \phi_{t}\right)\right) & \text { if } \varpi=u_{2}\end{cases}
$$

If the agent is in state $u_{1}$ he receives $\mathrm{UI}$, but with probability $\lambda_{l}$ he loses the benefit entitlement and moves to state $u_{2}$. After match destruction, an agent is always entitled to benefits ${ }^{11}$. $b_{\max }$ are statutory maximum UI payments. Both unemployment

\footnotetext{
${ }^{10} \Gamma$ is the only source of match effects in our model, which we interpret as firm productivity. However, one can broaden this interpretation to include match specific effects and, as Winfried Koeniger pointed out to us, differences arising from bargaining over quasi rents from capital.

${ }^{11}$ Low et al. (2010) and Ljungqvist and Sargent (2008) assume that entitlement is conditional on the separation being involuntary on part of the worker. We choose a different path in assuming that the cause of separation is unobservable to the UI agency.
} 
benefits and the value of leisure depend on the worker's idiosyncratic states:

$$
\begin{aligned}
b\left(A_{t}, \phi_{t}\right) & =r r_{b} \cdot \mathbb{E}\left[w_{t}\left(A_{t}, \Gamma_{t}, \phi_{t}\right) \mid A_{t}, \phi_{t}\right] \\
Z\left(A_{t}, \phi_{t}\right) & =r r_{Z} \cdot \mathbb{E}\left[w_{t}\left(A_{t}, \Gamma_{t}, \phi_{t}\right) \mid A_{t}, \phi_{t}\right]
\end{aligned}
$$

Expectations are taken over the range of acceptable job offers which themselves depend on $A_{t}$ and $\phi_{t}$. In the case of unemployment insurance this captures the fact that benefits depend on prior contributions. More productive workers earn higher wages and older workers likely contributed a longer time. In the case of the value of leisure, we choose this as the closest analogy to the homogeneous agent world. Giving everyone the same value of leisure would increase the amount of implied frictional wage dispersion. One can interpret this formulation as a reduced form for modeling wealth heterogeneity. More productive workers tend to have higher asset levels and unemployed workers deplete their assets over time.

In modeling productivity development we are guided by the finding of Dustmann and Meghir (2005), who show that the first two years of labor market experience raise wages substantially (6-10\% per year), while the return to experience is substantially lower afterwards $(0-1.2 \%)^{12}$. We therefore introduce a life cycle dimension where agents transit through two life cycle states $(\phi)$ with stochastic transition probabilities $p=\left(p_{1}, p_{2}\right)$. When the second shock hits, the agent dies and is replaced by an unemployed labor market entrant in state $u_{2}$ whose idiosyncratic log productivity is drawn from the distribution $N \sim N\left(\mu_{N}, \sigma_{N}^{2}\right)$.

The evolution of worker productivity depends on the agent's employment status and in case the agent is employed it also depends on his life cycle state:

$$
A_{t+1}= \begin{cases}\max \left(A_{t}+\nu(\phi)+\epsilon_{t}, \text { pmin }\right) & \text { if employed } \\ \max \left(A_{t}-\delta+\epsilon_{t}, \text { pmin }\right) & \text { if unemployed }\end{cases}
$$

$\delta$ represents skill depreciation while being unemployed, pmin is a subsistence level

\footnotetext{
${ }^{12}$ Dustmann and Meghir (2005) use German data, but have the advantage of identifying effects by using displaced workers. For U.S. data, Altonji and Williams (1998) come to similar results.
} 
of productivity and $\nu(\phi)$ is a drift term that depends on the life cycle state. $\epsilon$ is a productivity shock with $\epsilon \sim N\left(0, \sigma_{\epsilon}^{2}\right)$. We think of wage shocks as anything altering productivity such as demand shocks for specific skills or health shocks. The fact that net productivity growth can be negative means that our model also features wage cuts on the job.

Let $\omega$ be the exogenous match separation rate. Match shocks leave worker productivity unaffected but cause match dissolution. Examples can be demand shocks or financing shocks to the firm. Matches may also be dissolved endogenously as result of negative productivity innovations.

\section{Box 1: Model Timing}

1. The employed workers negotiate a wage with their firm.

2. Production takes place.

3. Some unemployed transit from $u_{1}$ to $u_{2}$.

4. The employed and unemployed experience productivity transitions according to their laws of motion.

5. Life cycle transitions take place. Agents die and are replaced.

6. Exogenous job destruction occurs. Agents becoming unemployed cannot search for employment within this period.

7. On the job offers realize.

8. Employed agents decide whether to quit and the unemployed with job offers decide whether to accept the job.

Our model allows employed workers to search for better job prospects. Following our discussion in Section 2.3, we model some job to job transitions as forced movements. An employed worker receives a job offer with probability $\lambda$ and can in general decide to stay with his old match, or form a new match. However, when receiving an outside offer, with probability $\lambda_{d}$ the offer is a forced movement and the outside option becomes unemployment. In our empirical section we show how to infer the structural parameters $\lambda$ and $\lambda_{d}$ from micro data on job transitions and wages.

At this point we need to make an assumption on how wage bargaining takes place. We assume firms cannot commit to a wage path ${ }^{13}$ and each period wages are renego-

\footnotetext{
${ }^{13}$ There is a growing literature including Mortensen (2003) and Flinn and Mabli (2008) arguing
} 
tiated by Nash-Bargaining ${ }^{14}$. We assume a worker always quits into unemployment before making a job to job transition. His outside option thus being unemployment with benefit entitlement when bargaining with the new firm. The timing within one model period is summarized in Box 1.

We can thus define the value of employment for each life cycle state $\left(V_{\phi}^{E}\right)$ and the value of unemployment $\left(V_{\phi, \varpi}^{U}\right)$ depending on worker's idiosyncratic productivity, firm productivity, and benefit entitlement. We state the Bellman equations describing the problems of agents in the first life cycle state as an example. The value of employment reads:

$$
\begin{aligned}
V_{1}^{E}\left(A_{t}, \Gamma_{t}\right)=w_{t}\left(A_{t}, \Gamma_{t}, 1\right)+\beta \mathbb{E}_{t}\{(1-\omega) & \\
{\left[\left(1-p_{1}\right)[(1-\lambda) H(1)+\right.} & \left.\lambda\left[\left(1-\lambda_{d}\right) \Omega_{E}(1)+\lambda_{d} \Lambda(1)\right]\right] \\
+p_{1}[(1-\lambda) H(2)+\lambda & {\left.\left.\left[\left(1-\lambda_{d}\right) \Omega_{E}(2)+\lambda_{d} \Lambda(2)\right]\right]\right] } \\
& \left.+\omega\left[\left(1-p_{1}\right) V_{1, u_{1}}^{U}\left(A_{t+1}\right)+p_{1} V_{2, u_{1}}^{U}\left(A_{t+1}\right)\right]\right\}
\end{aligned}
$$

$\mathbb{E}_{t}$ is the expectation operator given all information in period $t$. For clarity of presentation, we have defined conditional on life cycle state and benefit entitlement the upper envelopes for receiving a regular job offer on the job $\left(\Omega_{E}(x)\right)$, receiving a forced job offer $(\Lambda(x))$ and the decision to quit into unemployment voluntarily $(H(x))\left(\Gamma_{t+1}^{\prime}\right.$

that wage posting as in Burdett and Mortensen (1998) provides a worse representation of the data compared to Nash-Bargaining. Our discussion in section 2.3.1 can also be seen in this light.

${ }^{14}$ In the context of on the job search, the bargaining set may be non-convex and the NashBargaining solution therefore be undefined as discussed in Shimer (2006). As shown by Moscarini (2005) pp. 496, our set-up can be reconciled with Nash-Bargaining by implicitly assuming an English auction between incumbent and poaching firm in which firms do not play weekly dominant strategies. For details please refer to that paper. The resulting wage changes in our paper are equivalent to that assumption. 
is firm productivity at an outside job offer).

$$
\begin{aligned}
\Omega_{E}(x) & =\max \int\left\{V_{x}^{E}\left(A_{t+1}, \Gamma_{t+1}\right), V_{x, u_{1}}^{U}\left(A_{t+1}\right), V_{x}^{E}\left(A_{t+1}, \Gamma_{t+1}^{\prime}\right)\right\} d F \\
H(x) & =\max \left\{V_{x}^{E}\left(A_{t+1}, \Gamma_{t+1}\right), V_{x, u_{1}}^{U}\left(A_{t+1}\right)\right\} \\
\Lambda(x) & =\max \int\left\{V_{x}^{E}\left(A_{t+1}, \Gamma_{t+1}^{\prime}\right), V_{x, u_{1}}^{U}\left(A_{t+1}\right)\right\} d F
\end{aligned}
$$

Furthermore, there are two value functions for the unemployed with and without benefit entitlement. Conditional on receiving benefits, the value of unemployment solves:

$$
\begin{aligned}
& V_{1, u_{1}}^{U}\left(A_{t}\right)=b+ Z+\beta \mathbb{E}_{t}\left\{\left(1-\lambda_{l}\right)\right. \\
& \quad\left[\left(1-p_{1}\right)\left[p(\theta) \Omega_{U}\left(1, u_{1}\right)+(1-p(\theta)) V_{1, u_{1}}^{U}\left(A_{t+1}\right)\right]\right. \\
&\left.\quad+p_{1}\left[p(\theta) \Omega_{U}\left(2, u_{1}\right)+(1-p(\theta)) V_{2, u_{1}}^{U}\left(A_{t+1}\right)\right]\right] \\
&+\lambda_{l}\left[\left(1-p_{1}\right)\left[p(\theta) \Omega_{U}\left(1, u_{2}\right)+(1-p(\theta)) V_{1, u_{2}}^{U}\left(A_{t+1}\right)\right]\right. \\
&\left.\left.\quad+p_{1}\left[p(\theta) \Omega_{U}\left(2, u_{2}\right)+(1-p(\theta)) V_{2, u_{2}}^{U}\left(A_{t+1}\right)\right]\right]\right\}
\end{aligned}
$$

Once benefits expire, the agent's flow value is reduced to the utility of leisure / home production:

$$
\begin{aligned}
V_{1, u_{2}}^{U}\left(A_{t}\right)=Z+\beta \mathbb{E}_{t}\left\{\left(1-p_{1}\right)\left[p(\theta) \Omega_{U}\left(1, u_{2}\right)+(1-p(\theta)) V_{1, u_{2}}^{U}\left(A_{t+1}\right)\right]\right. \\
\left.+p_{1}\left[p(\theta) \Omega_{U}\left(2, u_{2}\right)+(1-p(\theta)) V_{2, u_{2}}^{U}\left(A_{t+1}\right)\right]\right\}
\end{aligned}
$$

where we defined the conditional upper envelope for receiving a job offer as $\Omega_{U}(x, \varpi)$.

$$
\Omega_{U}(x, \varpi)=\max \int\left\{V_{x}^{E}\left(A_{t+1}, \Gamma_{t+1}\right), V_{x, \varpi}^{U}\left(A_{t+1}\right)\right\} d F
$$

\subsection{The Firm Problem}

An entering firm's problem is described by its value to post a vacancy $\left(V^{I}\right)$. An open vacancy entails flow costs of $\varphi$ each period. We assume vacancies are homogeneous ex 
ante and the realization of the idiosyncratic productivity reveals only upon meeting a worker and entering into wage negotiations. If a worker is contacted, $\Gamma$ is drawn from $F^{15}$. There are three ways to fill a vacancy. First, an unemployed agent might be contacted, occurring with probability $q(\theta)$. Second, the firm might poach a worker that is employed and make him a job offer, which happens at rate $\frac{\lambda\left(1-\lambda_{d}\right)}{v}$. Or third, a worker might be offered the vacancy by a forced job movement, occurring at rate $\frac{\lambda \lambda_{d}}{v}$. Note that in any case the ex ante acceptance probability depends on the productivity of the vacancy. Given that firm and worker productivities are complements, higher productivity vacancies attract also lower productivity workers and are less likely to lose parts of their workforce to other firms. We relegate the further description of $\left(V^{I}\right)$ to Appendix A as it provides little additional intuition.

The value of a filled vacancy $V_{x}^{J}$ depends on the life cycle state of the matched employee and a firm employing someone in life cycle state 1 has value

$$
\begin{aligned}
& V_{1}^{J}\left(A_{t}, \Gamma_{t}\right)=y_{t}-w\left(A_{t}, \Gamma_{t}, 1\right)+\beta(1-\omega) \mathbb{E}_{t}\{ \\
&(1-\lambda)\left[\left(1-p_{1}\right) \Phi(1)+p_{1} \Phi(2)\right] \\
&\left.\quad+\lambda\left(1-\lambda_{d}\right) \eta\left(\Gamma_{t+1}\right)\left[\left(1-p_{1}\right) \Phi(1)+p_{1} \Phi(2)\right]\right\}
\end{aligned}
$$

where $\eta(\Gamma)$ is the probability that the worker stays with the firm when contacted from an outside firm, which is increasing in $\Gamma$. Moreover, we have defined the upper envelope $\Phi(x)$ indicating the match continuation choice conditional on the life cycle state and productivities:

$$
\Phi(x)=\max \left\{0, V_{x}^{J}\left(A_{t+1}, \Gamma_{t+1}\right)\right\}
$$

The equilibrium definition is standard and can be found in Appendix B.

\footnotetext{
${ }^{15}$ This can be rationalized by assuming that there is a match specific component in productivity.
} 


\subsection{Approximating the Wage Schedule}

To facilitate our subsequent analysis and to make our approach more comparable to standard microeconometric specifications we approximate the equilibrium wage schedule by a linear function. From the Nash-Bargaining solution it is obvious that $\log$ wages are not a linear function in worker and firm productivity. Figures III and IV plot $\ln (w)$ over worker and firm productivity for agents in life cycle state 2, holding the productivity of the other fixed at its mean value. The plots indicate that these functions can still be reasonably well approximated by a linear function. We asses this more formally by fitting a linear OLS regression to an economy generated by the true non-linear dynamics of our model. To be more specific, we simulate 50000 workers for 3 years from the stationary distribution, using our non-linear model. We then project the resulting data into a linear space employing the following regression:

$$
\ln \left(w_{i, t}\right)=\beta_{0}+\beta_{1} A_{i, t}+\beta_{2} \phi_{i, t}+\beta_{3} \Gamma_{i, t}+a_{i, t}
$$

Note, assuming the law of large number holds, the error term $a_{i, t}$ measures the approximation error that results from the linear projection. We obtain an $R^{2}$ above 0.9996, suggesting that the fit of the linear regression model is quite good. We continue to work from now on with the linear approximation (1) to our true nonlinear model.

\section{Parameterization}

We take a dual strategy in parameterizing to our model. A number of parameter values we take from other studies. This makes our results easily comparable. Also, for many of those parameters (discount factor and bargaining share, for example) our results are robust to variations. We come back to this point below. The particular focus of our paper requires us to take great care in calibrating worker and firm productivity dispersion and flow rates in and out of employment and between firms. Wherever possible, we therefore estimate our calibration targets for the related parameters using our own data set in order to insure consistency. Although 
Figure III:

Log Wages Over Individual Productivity

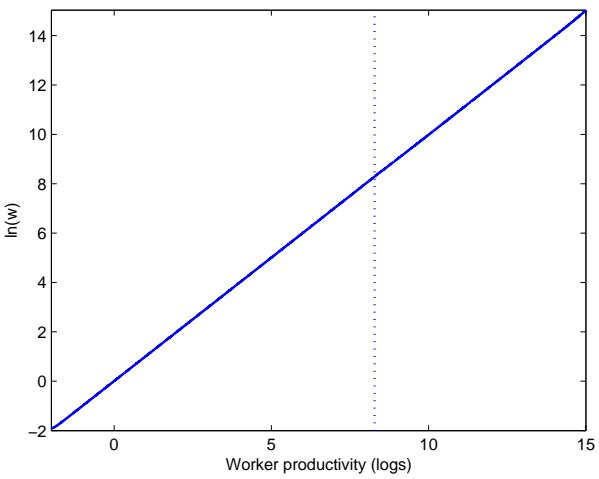

Notes: The graph displays the equilibrium log wage

schedule, fixing firm productivity at its median level

for workers in the second life cycle state. 95 percent

of all workers employed at such matches have

productivity levels below the dashed line.
Figure IV:

Log Wages Over Firm Productivity

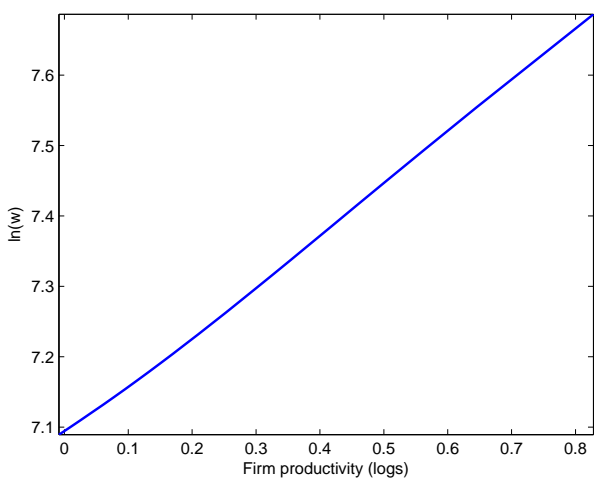

Notes: The graph displays the equilibrium log wage schedule, for workers with median productivity and in the second life cycle state.

the SIPP provides very detailed and extensive coverage, we cannot estimate all of the productivity parameters on the basis of our data set. We therefore take additional information from other micro studies carefully discussing each of our choices. This section proceeds as follows: We first discuss our calibration regarding nondistributional parameters (preferences, institutions, flow rates) in Section 4.1. In Section 4.2 we discuss productivity distributions and how we calibrate firm and idiosyncratic productivity dispersion. Our calibration is summarized in Table 3.

\subsection{Non-Distributional Parameters}

The model period is one month. The length of a period is of importance, because it puts an upper bound on the job offer probability $p(\theta)$ and the minimum duration of an unemployment spell. The first point is well supported by the data ${ }^{16}$, but the

\footnotetext{
${ }^{16}$ Holzer (1988) reports based on NLSY data that in the previous month 34 percent of the unemployed received at least one job offer and 12 percent received more than one offer. We are therefore confident that on average the unemployed worker does not receive more than one job offer
} 
second constraint is likely to be binding ${ }^{17}$.

We calculate the EU and UE rate of the US non-institutionalized population from CPS data for the years 1994-1995 following Fallick and Fleischmann (2004) for reasons discussed in Section 2. The exogenous job destruction rate $\omega$ is set such that the total destruction rate $d$, the sum of endogenous and exogenous movements from employment to unemployment, is 1.43 percent per month. We attach to $\xi$ a value that implies a monthly job finding rate of 0.271 .

We can use SIPP data to calibrate the parameters guiding on the job search. Information on EE movements and wage changes identify $\lambda$ and $\lambda_{d}$. We adjust $\lambda$ to imply that 2.45 percent of workers switch employers every period. As discussed previously, in order to correctly model the efficiency of on the job search, it is important to know how many of these movements result in wage improvements. Our identifying assumption for separating voluntary and involuntary movements is that voluntary movements always result in expected wage increases. In our data set, 34 percent of all EE movements result in a nominal wage loss. We set the percentage of forced movements $\left(\lambda_{d}\right)$ to 0.152 to match this statistic.

There is a large debate on the appropriate values for $\alpha, \iota$ and $\theta$ because of their importance for business-cycle fluctuations. Fortunately, in our steady state analysis these parameters do not affect our results because they only affect the job finding rate. Changing the parameters only leads to a recalibration of $\xi$. Hence, we normalize $\alpha=\iota=0.5$ and use $\varphi$ to match a labor market tightness of 0.6.

Consistent with findings from Siegel (2002) for average bond and stock returns, we set $\beta$ to imply a yearly interest rate of 4 percent. Next, we consider the flow value of unemployment. We set the replacement rate $r r_{b}$ to 25 percent. As argued in Hall and Milgrom (2008) this provides a parsimonious description of the system. The

per month.

${ }^{17}$ Clark and Summers (1979) report that based on the CPS 60 percent of all unemployed spells end within one month, while at any point in time, 69 percent of all unemployed have been out of a job for two months or more. These two figures can only coincide when a considerable fraction of unemployment spells end within less than one month. Therefore, our model cannot by construction match the high outflow rates within the first month. However, time disaggregation below one month is rather costly, because our numerical algorithm uses value function iteration, which converges at a rate of $1-\beta$. 
maximum UI benefit payment is set to $1168 \$$, which is the average across US states. The parameter determining the value of leisure $r r_{z}$ is set to 15 percent which yields a total replacement rate of 40 percent when entering into unemployment as in Shimer (2005). Last, we fix the probability for an unemployed worker to loose his benefit entitlement such that average entitlement is six months, which is the standard length in the US system outside of economic crisis.

In the presence of tenure and selection effects, it would be very hard (and potentially produce unreliable results) to estimate mean experience gains from our data set. We therefore use life cycle transition rates and drift terms in productivity during employment to match statistics found by Dustmann and Meghir (2005). Productivity is assumed to grow at an annual rate of 8 percent when employed during the first life cycle state and at a rate of 1 percent during the second. The transition probability between life cycle states $(p)$ is set such that agents spend on average 24 months in the first state and 480 in the second. Following Olivetti (2006), an unemployed worker experiences 2 percent skill depreciation per year ${ }^{18}$. The subsistence level of log-productivity (pmin) is set to -2 , which is never binding.

\subsection{Distributional Parameters}

We now describe the way we calibrate the variance of log-firm productivity $\sigma_{F}^{2}$, idiosyncratic productivity shocks $\sigma_{\epsilon}^{2}$ and initial worker productivities $\sigma_{N}^{2}$. None of the statistics is directly observable in the data because of measurement error. Additionally, agents endogenously select themselves into and out of employment and into employment with firms of specific productivity levels in response to idiosyncratic productivity developments. Instead, we identify them from our data as follows: Firm productivities are calibrated to match the excess variance of wage changes for job switchers over job stayers. $\sigma_{\epsilon}^{2}$ and $\sigma_{N}^{2}$ are chosen to jointly match the life cycle profile of wage inequality after controlling for idiosyncratic wage components absent from our model.

\footnotetext{
${ }^{18}$ This is also in line with Ljungqvist and Sargent (2008), who assume that skill depreciation is twice the rate of skill accumulation.
} 


\subsubsection{Measuring Firm Heterogeneity}

For identification of the firm productivity distribution, we require only a small set of assumptions. Other than specifying a general additive specification for log wages and assuming firm productivities to be log-normally distributed, our identification only relies on the assumption that measurement error for job switchers is not more severe than for job stayers ${ }^{19}$.

In our SIPP data, we assume that wages are generated by:

$$
\ln \left(w_{i, t}\right)=\alpha_{0}+\alpha_{1} d_{t}+\alpha_{2} Z_{i}+\beta_{2} \Gamma_{i}+e_{i, t}
$$

where $d_{t}$ captures aggregate states, such as TFP and $Z_{i}$ is a vector of idiosyncratic components. We split the unobservable $e_{i, t}$ into two parts:

$$
e_{i, t}=r_{i, t}+\beta_{1} A_{i, t}
$$

As in the model, $A_{i, t}$ is assumed to follow a random walk with drift and innovations $\epsilon_{i, t}$ while $r_{i, t}$ captures measurement error. For our present purpose, we have to make no further assumptions regarding the distributional properties of measurement error.

First-differencing eliminates the idiosyncratic wage components ${ }^{20}$. As mentioned above, we only observe a self-selected subset of the realizations of $\Gamma$ and $\epsilon$ as agents can quit into unemployment after negative productivity shocks and refuse wage offers by firms less productive than their present employer. The subsets of observed realizations $\Gamma^{o b s}$ and $\epsilon^{o b s}$ are themselves random variables, which follow distributions of unknown functional forms.

We can now define observed wage growth when a job to job transition takes place

$$
\Delta \ln \left(w_{i, t}^{b}\right)=\nu+\kappa_{t}+\beta_{2}\left[\Gamma_{i}^{o b s}-\Gamma_{i-1}^{o b s}\right]+\beta_{1} \epsilon_{i, t}^{o b s}+\Delta r_{i, t}
$$

\footnotetext{
${ }^{19}$ As discussed in the appendix, we are excluding from our sample those individuals who are holding multiple jobs after a transition to rule out this source of additional reporting error.

${ }^{20}$ In our estimations, we also checked for idiosyncratic differences in wage growth by including gender, race, industry and regional dummies. These variables were neither individually nor jointly significant.
} 
and when no such transition takes place

$$
\Delta \ln \left(w_{i, t}^{w}\right)=\nu+\kappa_{t}+\beta_{1} \epsilon_{i, t}^{o b s}+\Delta r_{i, t}
$$

where $\kappa_{t}=\alpha_{1}\left(d_{t}-d_{t-1}\right)$. After regressing out constant and time dummies, we obtain the residual excess variance of job movers relative to job stayers ${ }^{21}$ :

$$
\operatorname{Var}\left[\Delta \ln \left(\hat{w}_{i, t}^{b}\right)\right]-\operatorname{Var}\left[\Delta \ln \left(\hat{w}_{i, t}^{w}\right)\right]=\beta_{2}^{2} \operatorname{Var}\left[\Gamma_{i}^{o b s}-\Gamma_{i,-1}^{o b s}\right]+2 \beta_{1} \beta_{2} \operatorname{Cov}\left[\epsilon_{i, t}^{o b s}\left(\Gamma_{i}^{o b s}-\Gamma_{i,-1}^{o b s}\right)\right]
$$

where we have invoked the assumption that measurement error is uncorrelated with the event of job switching.

In Section 3.4 we demonstrated that the wage schedule in our model can be very accurately approximated by a log-linear approximation analogous to equation (2) given by equation (1). Equation (3) therefore also approximately holds in our model and we can use it as a calibration target for $\sigma_{F}^{2}$. All endogenous sorting that causes the observed productivity distribution in the data to differ from the true one is also present in our model.

\subsubsection{Calibrating Idiosyncratic Productivity Uncertainty}

In principle, we could derive a moment condition similar to the one above in order to identify idiosyncratic productivity uncertainty (see Meghir and Pistaferri (2004) for more details). Meanwhile, while the identification of firm productivity only required two consecutive wage observations, the maximum spell length of 36 months in the SIPP now becomes more of on an issue. We therefore opt for a different calibration strategy. We first regress out idiosyncratic wage components absent from our model (gender, race, marriage and disability) ${ }^{22}$. We then choose $\sigma_{N}^{2}$ to match initial wage

\footnotetext{
${ }^{21}$ We delete the top and bottom $0.75 \%$ of the wage growth observations to get rid of reporting error.

${ }^{22}$ Wages in our model are a function of productivities. We purify our data of these effects which are well-known drivers of wages because we think them inadequately represented by our model set-up. Gender and race biases are likely the result more of discrimination than a representation of productivity. Marriage stands in for a joint labor supply decision absent from our model as we do not model joint intra-household decisions. Disability likely does represent productivity, but not in a way adequately captured by our model.
} 
Table 3: Calibration

\begin{tabular}{lr}
\hline Variable & Target \\
\hline \hline$\beta=0.9967$ & $4 \%$ yearly interest rate \\
$\varphi=1427$ & $\theta=0.6$ \\
$\alpha=\iota=0.5$ & Normalization \\
$r r_{b}=0.25$ & $\frac{b_{\text {mean }}}{w_{\text {mean }}}=25 \%$ \\
$r r_{Z}=0.15$ & $\frac{Z_{\text {mean }}}{w_{\text {mean }}}=15 \%$ \\
$b_{\text {max }}$ & $1168 \$$ \\
$\lambda_{l}=0.16$ & $d=0.0143$ \\
$\omega=0.01$ & UE flow of 0.271 \\
$\xi=0.48$ & EE flow of 0.0245 \\
$\lambda=0.0845$ & month benefit duration \\
$\lambda_{d}=0.152$ & of EE lead to wage cuts \\
\hline$\nu(1)=0.0067$ & productivity growth \\
$\nu(2)=0.00083$ & 2 productivity growth \\
$p_{1}=0.04$ & 40 years in 1st life cycle \\
$p_{2}=0.002$ & $2 \%$ skill depreciation \\
$\delta=0.00167$ & Normalization \\
$p m i n=-2$ & Equation $(3)=0.055$ \\
\hline$\sigma_{F}=0.342$ & Life-cycle wage profile \\
$\sigma_{\epsilon}=0.018$ & Life-cycle wage profile \\
$\sigma_{N}=0.28$ & Estimation \\
$\sigma_{\iota}=0.0236$ & Mean monthly wage $2070 \$$ \\
$\mu_{N}=6.88$ &
\end{tabular}

Notes: The first column states the calibrated variable and the value and the second states the relevant moment.

inequality and $\sigma_{\epsilon}^{2}$ to match the increase in inequality over the life cycle.

Lastly, an important part of wage fluctuations may actually be the result of measurement error. To assure robustness of our results, we explicitly model measurement error in our baseline calibration. At this point, we need to make further assumptions regarding its statistical properties. Following Meghir and Pistaferri (2004), we postulate an $M A(q)$ process (i.e. $\left.r_{i, t}=\Theta(q) \iota_{i, t}=\iota_{i, t}-\sum_{j=1}^{q} \theta_{j} \iota_{i, t-j}\right)$. Given that studies on annual wage growth typically assume iid measurement error, we fix $q$ at 12 . Assuming $\mathbb{E}\left(\epsilon_{i, t}^{o b s} \epsilon_{i, t-j}^{o b s}\right)=0 \forall j \neq 0$ the parameters $\Theta(12)$ and $\sigma_{\iota}$ can be obtained using 
Maximum Likelihood estimation and Kalman filtering ${ }^{23}$. Appendix C.2.2 supplies further detail on the procedure.

\section{Results}

We now present the main results of our paper. In Section 5.1, we demonstrate that the frictional wage dispersion present in our model is of the size estimated in the data. We then proceed to investigate the importance of the different channels in expanding the range of job offers acceptable to the workers. We demonstrate that our process for general human capital and the possibility to search on the job are both crucial ingredients in allowing the model to match the data. Shutting down either of the three channels: skill acquisition in employment, skill depreciation in unemployment or on the job search significantly shrinks the set of acceptable job offers and consequently frictional wage dispersion. Limited UI duration is only of second order importance. Given our calibration target, a job ladder model with initial worker heterogeneity turns out to be rival specification capable of producing empirically observed residual dispersion. However, it largely overstates the gains of on the job search by neglecting the one third of job to job movements resulting in wage losses in the data.

In Section 5.2, we demonstrate that our model also produces a good representation of the empirical wage distribution. After discussing the structurally inferred parameters of the wage offer distribution and of idiosyncratic wage uncertainty, we determine the relative contributions of firm dispersion, productivity development and the distribution of workers over firms to overall wage dispersion. Our results attribute about 17.5 percent of wage inequality to the presence of the search friction. The on the job search model neglecting forced movements yields a much larger contribution of over 40 percent.

\footnotetext{
${ }^{23}$ We thank Johannes Pfeifer for providing us the Kalman filtering routine.
} 


\subsection{Frictional Wage Dispersion and its Causes}

\subsubsection{Frictional Wage Dispersion in the Baseline Specification}

Table 4: Frictional Wage Dispersion

\begin{tabular}{c|c|c|c|c|c|c|c}
\hline \multicolumn{3}{c|}{ Mean-Min Ratio } & \multicolumn{2}{c|}{ Gini } & \multicolumn{2}{c}{$\operatorname{Var}\left(\log \left(\tilde{w}_{i t}\right)\right)$} \\
\hline \hline & & Model & Data & Model & Data & Model & Data \\
\hline \multirow{4}{*}{ Pctl. } & Min & 2.57 & & & & & \\
& $1^{\text {st }}$ & 1.45 & 2.18 & 0.0894 & 0.091 & 0.026 & 0.031 \\
& $5^{\text {th }}$ & 1.38 & 1.48 & & & & \\
& $10^{t h}$ & 1.31 & 1.31 & & & & \\
\hline
\end{tabular}

Notes: The table compares frictional wage dispersion generated by the baseline specification to residual wage dispersion in the 1993 SIPP. We report the Mm-ratio in the data using the 1st, 5th, and 10th percentile as possible minimum wages. For comparability, we report the corresponding statistic in the data as well.

In our model, leaving out measurement error for the moment, workers of identical idiosyncratic characteristics may be earning different wages as they are employed with firms of different productivities or due to measurement error. Using our approximated wage schedule in equation (1) frictional wages can be expressed as:

$$
\ln \left(\hat{w}_{i, t}\right)=\beta_{3} \Gamma_{i, t}+r_{i, t}
$$

In Table 4, we compare the frictional wage dispersion in our model to the amount of residual wage dispersion present in the data by comparing the moments reported in Section 2.2: the mean to minimum ratio advocated by HKV, the Gini coefficient and the variance of log residual wages. Our model successfully reproduces the amount of residual inequality in the data. In our baseline specification, the mean residual wage paid is 2.57 time the smallest observation. This is comparable, though slightly larger, to the Mm-ratio of 2.18 when taking the first percentile in the data to be the minimum wage. When looking at higher percentiles, model and data line up closely as well. Also the other statistics look favorable: the Gini coefficient matches up almost exactly and our model explains 84 percent of the variance of residual log wages in 
the data. When comparing different model specifications in our subsequent analysis, we only report changes in the Mm-ratio. This increases clarity of presentation and facilitates comparison with other studies (foremost HKV themselves) that report this summary statistic. When using percentiles as minimum wage, is also has the advantage of being robust to classical measurement error.

\subsubsection{Sources of Frictional Inequality}

We now want to analyze how the details of our model specification interact with the range of job offers acceptable to the worker given the distribution of firm productivities in our baseline. We therefore resolve a number of restricted versions, each time excluding or modifying one of the main channels and recalibrating to the flow rates, the flow value of unemployment and the residual wage profile. In each calibration, the unemployed sample at most one job offer a month, which imposes an upper bound on the flow value of unemployment for some of the experiments. Table 5 reports the resulting frictional wage dispersion and replacement rates.

Table 5: Contributions to Frictional Wage Dispersion

\begin{tabular}{|c|c|c|c|}
\hline \multicolumn{2}{|c|}{ Specification } & Mm-Ratio & $r r_{b}+r r_{z}$ \\
\hline \multicolumn{2}{|c|}{ Baseline } & 2.57 & 0.4 \\
\hline A & $\begin{array}{l}\text { No learning on the job } \\
(\nu(\phi)=0)\end{array}$ & 1.43 & 0.4 \\
\hline B & $\begin{array}{l}\text { No skill depreciation } \\
(\delta=0)\end{array}$ & 1.98 & 0.4 \\
\hline $\mathrm{C}$ & $\begin{array}{l}\text { No search on the job } \\
\lambda=0\end{array}$ & 1.19 & 0 \\
\hline $\mathrm{D}$ & $\begin{array}{l}\text { Infinite UI } \\
\left(\lambda_{l}=0\right)\end{array}$ & 2.35 & 0.4 \\
\hline
\end{tabular}

Notes: The table displays the frictional wage dispersion (FWD) for five different model specifications that differ from our baseline model by some parameter restriction.

It turns out that the main driver behind our results is the interaction of our process for general human capital with the possibility to search on the job. Spec- 
ifications $\mathbf{A}$ to $\mathbf{C}$ turn off each of those channels one after another. When setting expected experience gains during employment to zero frictional wage dispersion falls to only 1.43. As potential experience gains are equal in all firms, being employed at all becomes much more important than in which firm specifically. The same argument applies to the effects of skill depreciation (specification B) even though its effects are less pronounced. When setting $\delta$ to zero, the mean-min ratio drops to 1.98, which is still sizable but a substantial drop from 2.57. When denying workers the possibility to search on the job, the mean-min ratio plummets to 1.19 and no positive replacement rates are able to match observed flow rates. Finally, as demonstrated in specification $\mathbf{D}$, the limited payout duration of unemployment benefits is only of second order importance to the empirical success of our model.

We stressed previously the importance of accounting for job to job transitions resulting in wage losses when inferring search efficiencies from EE flow rates. In the absence of forced movements, we could generate any value for the mean-min ratio as workers would accept even negative wages. There are two reasons for this. First, if a job offer is a forced one, moving is almost always preferred to quitting into unemployment. Second, forced job movements decrease the rate at which agents climb up the productivity ladder of firms, making future job offers more likely to be better than today's offer. In consequence, search on the job is less efficient in a model featuring forced job movements. The value of employment decreases relative to the value of unemployment which again decreases frictional wage dispersion.

\subsubsection{A competing explanation}

Our previous analysis has identified on the job search as an important channel in understanding frictional wage dispersion. Indeed, one might ask how far a more "standard" on the job search specification would go on its own in explaining the data when calibrating it to observed flow rates only and ignoring forced movements. We discuss such an experiment in this section. The combination of a job-ladder model with heterogeneous initial worker productivities and general human capital uncertainty (but no trend growth on and off the job) calibrated to our targets by itself 
Table 6: Wage changes from job to job movements

\begin{tabular}{lrr}
\hline Specification & Avg. gain & Avg. loss \\
\hline \hline Data & 0.0203 & -0.22 \\
\hline Baseline & 0.069 & -0.21 \\
\hline Job ladder model & & \\
$\nu(1)=\nu(2)=0=\delta \lambda_{l}=0$ & 0.26 & -0.07 \\
\hline
\end{tabular}

Notes: The table displays the model baseline specification with a pure on the job search specification on their implications for job to job transitions. Statistics are the resulting average wage gain upon job movement and the average wage loss, conditional on observing a loss. Data refers to computation from the SIPP for nominal wages.

yields an Mm-ratio of 2.83 with solidly positive replacement rates $^{24}$. Given our previous estimates, this appears to be an empirically successful alternative explanation.

As discussed in Section 2.3.1, however, these model types seem to largely overstate the efficiency of on the job search by ignoring the frequent occurrence of job to job transitions resulting in wage losses. We therefore take the ability to realistically account for wage dynamics upon job to job movement as a means of discriminating between these rival model specifications. The results are displayed in Table 6.

In the data, job to job movements on average result in wage gains of 2 percent. Conditional on suffering a wage loss upon movement, workers lose 22 percent of their previous wages. Our baseline specification fares quite well in reproducing these statistics. Wage gains are too high, but the order of magnitude is comparable. The model does well in reproducing the large conditional wage losses. In the job-ladder model, average wage gains of 26 percent are much too large compared to the data. Since workers in this model only transit to more productive firms, the wage losses are only observed as result of a negative productivity shock or of measurement error. A conditional 7 percent average wage loss clearly fails in this respect. We will come back to this specification in Section 5.2.3 when discussing structural inference.

\footnotetext{
${ }^{24}$ Hornstein et al. (2011) also consider a job ladder model and obtain Mm-ratios between 1.16 and 1.27 for a replacement rate of 0.4 . However, the presence of individual productivity heterogeneity in our model implies heterogeneous reservation wages. In consequence, the homogeneous job offer arrival rate and the EU flow rate are no longer identical which in our case accounts for the much large frictional wage dispersion.
} 


\subsection{Wage Dispersion}

\subsubsection{Overall Wage Dispersion in the Model and in the Data}

Confident of having established the main channels shaping frictional wage inequality, we now use our calibrated baseline for structural inference regarding the sources of wage inequality. The literature so far has produced a wide range of estimates regarding the relative importance of differing initial abilities $\left(\sigma_{N}\right.$, in our model), idiosyncratic productivity uncertainty $\left(\sigma_{\epsilon}\right)$ and the search friction $\left(\sigma_{F}\right.$ and a sorting term to be introduced below).

In order to assure that our model can be used to make such statements, we first have to evaluate whether it reproduces a wage distribution comparable to what we see in the data. As discussed previously, there are a few well-known wage determinants in the data that our model is not designed to include. In what follows, we therefore first regress log-wages in our data on a constant and dummies for disability, gender, marriage status, and race. These factors account for 10 percent of log-wage variation. The resulting residual distribution ${ }^{25}$ is what we will be comparing our model wage distribution to. Figure V plots the kernel estimator of the aggregate density function of wages after transforming the data back to levels against its model counterpart ${ }^{26}$. It features the characteristic right skew of the observed wage distribution in the data. Figure VI displays the theoretical and empirical Lorenz curves of wages. Our model economy exhibits slightly more wage inequality, but the difference is negligible. Overall, the results reassure us that our model economy picks up the key moments of wage inequality present in the data.

\subsubsection{Sources of Wage Inequality}

We start by discussing the wage offer distribution and the distribution of idiosyncratic wage risk. Both can be derived from our wage schedule given in equation (1). The

\footnotetext{
${ }^{25}$ This should of course not be confused with the residual distribution we used as a measure for frictional wage dispersion.

${ }^{26}$ We truncate our observed wage data at the bottom and top $1 \%$ wage observations to delete outliers. We do the same adjustment to our simulated data in this section.
} 
Figure V:

The Wage Distribution

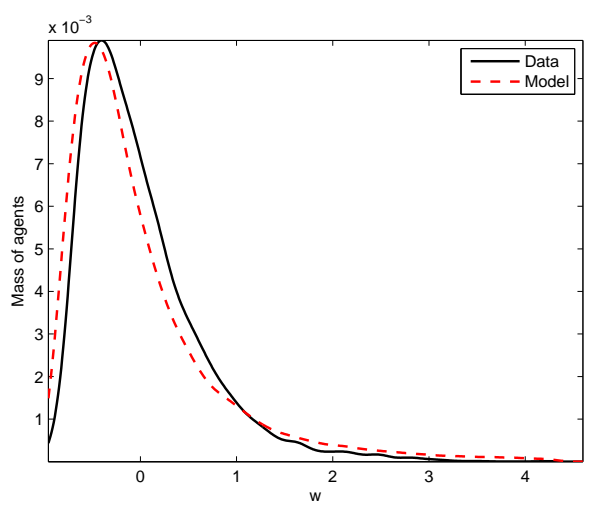

Notes: The Figure displays the theoretical PDF of workers over wages, smoothed with a kernel

estimator. Both distributions have been demeaned.
Figure VI:

Empirical and Theoretical Lorenz Curve

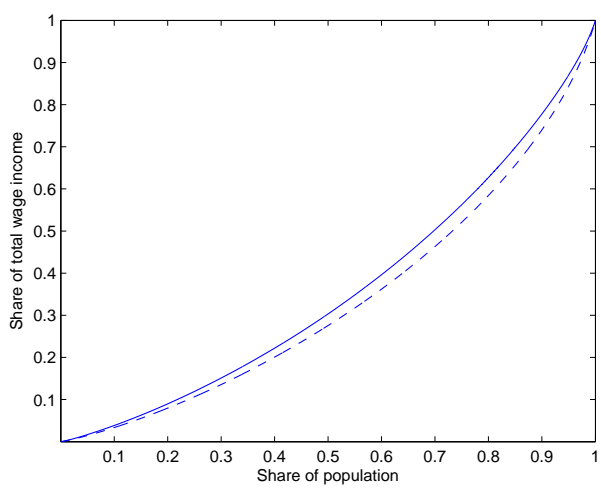

Notes: The straight line is the Lorenz curve of wages in SIPP data. The dashed line is the Lorenz curve from the theoretical model.

results are displayed in the first line of Table 7 . Our estimate for $\sqrt{\beta_{1}} \sigma_{\epsilon}$ implies an annual standard deviation for the permanent component of wages of 0.0624 . To put our results into perspective, Low et al. (2010), also using the 1993 SIPP, estimate a standard deviation for the wage offer distribution of 0.23 and of 0.103 for annual productivity innovations. Our estimates attribute more ex-ante wage uncertainty to the firm component as opposed to idiosyncratic productivity uncertainty.

To evaluate the contributions of productivity differences, firm differences, worker selection into matches given the stationary distribution of our model, we simulate a panel of 15000 workers' histories for 43 years. Consider the following variance decomposition based on a slightly modified version of (1), which we estimate separately for each age cohort in our simulated data

$$
\operatorname{Var}\left(\ln \left(w_{i}\right)\right)=\beta_{1}^{2} \operatorname{Var}\left(A_{i}\right)+\beta_{2}^{2} \operatorname{Var}\left(\Gamma_{i}\right)+2 \beta_{1} \beta_{2} \operatorname{Cov}\left(A_{i}, \Gamma_{i}\right)+\operatorname{Var}\left(r_{i}\right)
$$

Figure VIIA displays the results. Measurement error does not appear to be very important. Sorting of workers over firm productivities has a mild negative effect. 
Table 7: Wage Offer Distribution and Idiosyncratic Risk

\begin{tabular}{lrc}
\hline Specification & $\sqrt{\beta_{3}} \sigma_{F}$ & $\sqrt{\beta_{1}} \sigma_{\epsilon}$ \\
\hline \hline Baseline & 0.29 & 0.0180 \\
\hline $\begin{array}{l}\text { Job ladder model } \\
\nu(1)=\nu(2)=0=\delta \lambda_{l}=0\end{array}$ & 0.44 & 0.0156 \\
\hline
\end{tabular}

Notes: The table displays the standard deviations of the wage offer distribution and of the idiosyncratic wage shock, derived from the wage schedule in equation (1). The first line refers to the baseline specification and the second one to a calibration of on the job search only.

For young workers, firm heterogeneity explains more than forty percent of overall log wage variance but that number quickly drops as workers' employment histories become more divers. Our model identifies worker heterogeneity as the dominant factor in explaining variations in wages and this effect is increasing in age ${ }^{27}$. In a population weighted average, frictional wage dispersion accounts for 19.45 percent of wage inequality within our model. Given that we eliminated 10 percent of wage variation through our fixed effect regression, this implies frictional inequality to account for 17.5 percent of overall wage inequality present in our data.

\subsubsection{Neglecting Wage Cuts in On the Job Search Models}

The literature so far has produced a wide range of estimates regarding the contribution of the search friction to overall inequality. Estimates range from 6 percent in Hagedorn and Manovskii (2010) to as high as 50 percent in Postel-Vinay and Robin (2002). Our estimate comes out in the lower part of that spectrum. Using our model, we can show why on the job search models like the one estimated in Postel-Vinay and Robin (2002) are likely to produce higher estimates for the contribution of frictional wage dispersion. These models have so far attributed all employment to employment

\footnotetext{
${ }^{27}$ Note that this finding is not in contrast to the fact that a Mincer wage equation with worker fixed effects explains only little variation in wages. Individual productivity is only partially correlated with initial productivity and all changes in productivity are time varying unobservables to the econometrician. The typical worker observables included in the Mincer wage equation can at best proxy for these variations.
} 
Figure VII: Contribution of Search Frictions to Overall Wage Dispersion

(A) Baseline

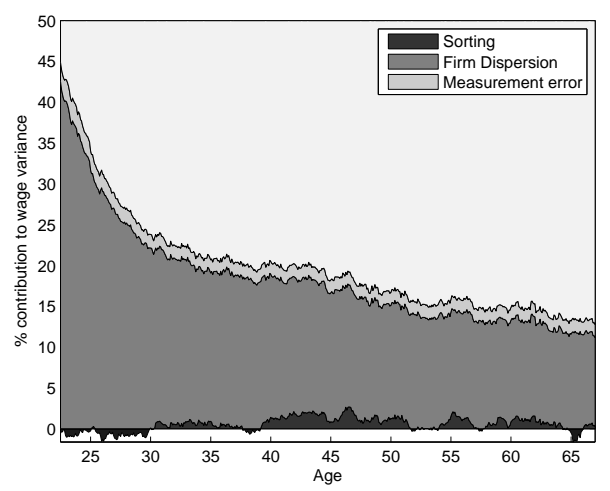

(B) Job ladder model

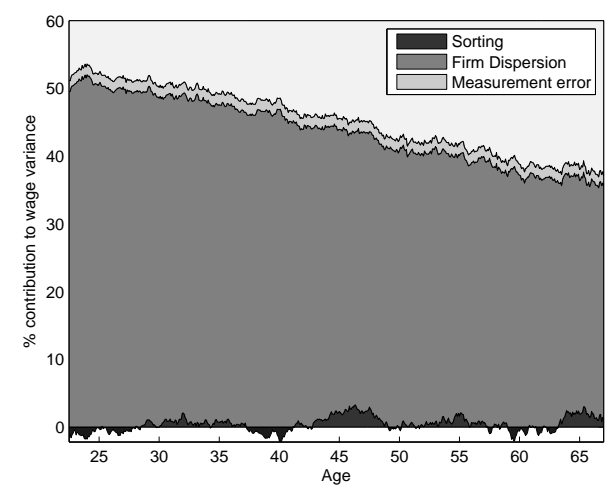

Notes: The graphs display the contribution of sorting (black area), firm effects (dark gray area), and measurement error(medium gray area) to the variance of log wages, conditional on age. Panel (A) refers to our baseline specification. Panel (B) results from a job ladder model with idiosyncratic productivity risk.

transitions to upwards movements on a wage ladder (at least in expectations). As argued above, this implicit assumption overstates the efficiency of on the job search.

We perform the same structural decomposition for the job-ladder version of our model. The result can be seen in Figure VIIB. The cross-sectional average for the contribution of frictional wage dispersion more than doubles to about 45 percent (40 percent of wage variation in the data) with values as high as 50 percent for the youngest workers and decreasing much more slowly over the life cycle. The bottom line in Table 7 tells a similar story. The calibrated standard deviation for the wage offer distribution increases by over 50 percent while idiosyncratic wage uncertainty drops 15 percent. The two model versions tell rather different stories about the sources of life-time wage inequality. 


\section{Conclusion}

Structural estimation of search models has frequently been used to circumvent the problem of finding instruments in quantifying sources of wage risk and inequality. One empirical appeal in using a search structure for estimation is its theoretical ability to rationalize the large amount of wage inequality that cannot be explained by worker observables. The search friction makes looking for the best possible wage offer costly and induces workers of identical characteristics to accept a range of different job offers.

Yet, as Hornstein et al. (2011) point out in a recent contribution, it is a builtin feature in many of the commonly used search frameworks that they can only rationalize a small portion of the empirically observed residual inequality as frictional inequality given reasonable parameter values for discount factor and replacement rate. When using them in structural estimations on wage data, the researcher is therefore bound to either obtain unreasonably low estimates for discount factor and replacement rate or to fix them a priori and attribute most of wage inequality to measurement error. In our view, however, this conclusion should be drawn from a model that theoretically could account for the observed residual inquality.

In this paper, we therefore build a rich structural model capable of rationalizing empirically observed residual inequality as frictional while also estimating and including measurement error. We trace out the different channels influencing the worker decision and conclude that idiosyncratic productivity development and on the job search are the driving factors behind frictional inequality. Concerning the latter, we argue that a model featuring job to job transitions needs be able to simultaneously account for wage movements upon transition. In particular, it must also address the one third of job switches which result in workers taking pay cuts. This feature allows us to discriminate between our model and a more standard wage ladder model in terms of their ability to best match the data.

It also leads us to make a second more general point regarding the structural inference of sources of wage inequality. Job to job transitions in the data are large and an obvious source of wage mobility. Yet, many on the job search models make 
the implicit assumptions that outside offers on the job are only accepted when they are associated with expected wage improvements. In order to rationalize the size of worker flows, these models therefore end up with a very high estimated search efficiency. When simultaneously inferring the wage offer distribution from wage volatility for job switchers, these models are bound to exaggerate the importance of the search friction in generating overall inequality. We find search related inequality to be responsible for 17.5 percent of overall inequality. When inferring the same number from a wage ladder model neglecting the frequent loss-making job to job transitions, it doubles to more than 40 percent. This finding explains some of the higher estimates in the literature regarding the importance of search frictions for wage inequality. 


\section{References}

Altonji, Joseph G. and Nicolas Williams, "The Effects of Labor Market Experience, Job Seniority, and job Mobility on Wages," Research in Labor Economics, 1998, 17, 233-276.

Bontemps, Christian, Jean-Marc Robin, and Gerard J. Van den Berg, "An Empirical Equilibrium Job Search Model with Search on the Job and Heterogeneous Workers and Firms," International Economic Review, November 1999, 40 (4), 1039-74.

_, _, and Gerard J. van den Berg, "Equilibrium Search with Continuous Productivity Dispersion: Theory and Nonparametric Estimation," International Economic Review, May 2000, 41 (2), 305-58.

Burdett, Ken, Carlos Carrillo-Tudela, and Melvyn Coles, "Human Capital Accumulation and Labour Market Equilibrium," Discussion Paper 4215, Institute for the Study of Labor (IZA) June 2009.

Burdett, Kenneth and Dale T. Mortensen, "Wage Differentials, Employer Size, and Unemployment," International Economic Review, May 1998, 39 (2), 257-73.

Carrillo-Tudela, Carlos, "Job Search, Human Capital and Wage Inequality," mimeo, University of Leicester Feb 2010.

Center for Economic and Policy Research, "SIPP Uniform Extracts, Version 2.1.5," 2010.

Clark, Kim B. and Lawrence H. Summers, "Labor Market Dynamics and Unemployemnt: A Reconsideration," Brookings Papers on Economic Activity, 1979, $10(1), 13-72$.

Dustmann, Christian and Costas Meghir, "Wages, Experience and Seniority," Review of Economic Studies, 01 2005, 72 (1), 77-108. 
Fallick, Bruce and Charles A. Fleischman, "Employer-to-employer flows in the U.S. labor market: the complete picture of gross worker flows," Finance and Economics Discussion Series 2004-34, Board of Governors of the Federal Reserve System (U.S.) 2004.

Flinn, Christopher and James Mabli, "On-the-Job Search, Minimum Wages, and Labor Market Outcomes in an Equilibrium Bargaining Framework," Carlo Alberto Notebooks 91, Collegio Carlo Alberto 2008.

Hagedorn, Marcus and Iourii Manovskii, "Search Frictions and Wage Dispersion," mimeo, University of Pensylvania 2010.

Hall, Robert E. and Paul R. Milgrom, "The Limited Influence of Unemployment on the Wage Bargain," American Economic Review, September 2008, 98 (4), 16531674.

Holzer, Harry J., "Search Method Use by Unemployed Youth," Journal of Labor Economics, 1988, 6 (1), 1-20.

Hornstein, Andreas, Per Krusell, and Giovanni L. Violante, "Frictional Wage Dispersion in Search Models: A Quantitative Assessment," NBER Working Papers 13674, National Bureau of Economic Research, Inc November 2007.

_, _, and _, "Frictional Wage Dispersion in Search Models: A Quantitative Assessment," American Economic Review, 2011, p. Forthcomming.

Jolivet, Gregory, Fabien Postel-Vinay, and Jean-Marc Robin, "The empirical content of the job search model: Labor mobility and wage distributions in Europe and the US," European Economic Review, May 2006, 50 (4), 877-907.

Ljungqvist, Lars and Thomas J. Sargent, "Two Questions about European Unemployment," Econometrica, 01 2008, 76 (1), 1-29.

Low, Hamish, Costas Meghir, and Luigi Pistaferri, "Wage Risk and Employment Risk over the Life Cycle," American Economic Review, September 2010, 100 (4), $1432-67$. 
Mazumder, Bhashkar, "New Evidence on Labor Market Dynamics Over the Business Cycle," Economic Perspectives, 2007, 2007 (Q1), 36-46.

Meghir, Costas and Luigi Pistaferri, "Income Variance Dynamics and Heterogeneity," Econometrica, Jannuary 2004, 72 (1), 1-32.

Mortensen, Dale, Wage Dispersion: Why are Similar Workers Paid Differently, MIT Press, 2003.

Moscarini, Giuseppe, "Job Matching and the Wage Distribution," Econometrica, 03 2005, 73 (2), 481-516.

- and Kaj Thomsson, "Occupational and Job Mobility in the US," Scandinavian Journal of Economics, 2007, 109 (4), 807-836.

Nágipal, Evá, "On the Extend of Job-to-Job Transitions," mimeo, Northwestern University 2005.

Papp, Tamás, "Frictional Wage Dispersion with Bertrand Competition: An Assessment," mimeo, Institute for Advanced Studies February 2011.

Postel-Vinay, Fabien and Jean-Marc Robin, "Equilibrium Wage Dispersion with Worker and Employer Heterogeneity," Econometrica, 2002, 70 (6), 2295-2350.

Shimer, Robert, "The Cyclical Behavior of Equilibrium Unemployment and Vacancies," American Economic Review, 2005, 95 (1), 25-49.

_ , "On-the-job search and strategic bargaining," European Economic Review, May 2006, $50(4), 811-830$.

Siegel, Jeremy, Stocks for the Long Run, McGraw-Hill, 2002.

Stinson, Martha, "Technical Describtion of SIPP Job Identification Number Editing in the 1990-1993 SIPP Panels," mimeo, U.S. Census Bureau July 2003. 


\section{A The Value of a Vacancy}

Here we supply the calculation of vacancy value which for reasons of parsimony we excluded from the main text. To evaluate future profit prospects and acceptance probabilities, the entrepreneur needs to know the stationary distribution of the unemployed over productivity, benefit states and life cycle states, which has density $f(\psi)$. Moreover, he needs to know the distribution of workers over their productivities, life cycle states and other firms' productivities, which has density $f(\chi)$. Summarizing the workers' states in $s=(A, \Gamma, \phi)$, the value of posting a vacancy $\left(V^{I}\right)$ is the expectation of firm value $V_{x}^{J}$ over productivity and life cycle states, minus the vacancy posting costs $\varphi$ :

$$
\begin{aligned}
& V^{I}=-\varphi+\beta \mathbb{E}_{t}\left\{q(\theta)\left[\iiint V_{x}^{J}\left(s^{\prime}\right) f(\psi) d \psi q_{1}(s) d s d F\right]\right. \\
& +\frac{\lambda\left(1-\lambda_{d}\right)}{v}\left[\iiint V_{x}^{J}\left(s^{\prime}\right) f(\chi) d \chi q_{2}(s) d s d F\right] \\
& \left.\quad+\frac{\lambda \lambda_{d}}{v}\left[\iiint V_{x}^{J}\left(s^{\prime}\right) f(\chi) d \chi q_{3}(s) d s d F\right]\right\}
\end{aligned}
$$

where $q_{1}, q_{2}, q_{3}$ are the probabilities that a worker will accept the job offer given that he is of type $A$ and in life cycle $\phi$ and the firm is of type $\Gamma$. These probabilities are strictly increasing in $\Gamma$, as a more productive firm finds it easier to attract workers. We set the continuation value of a vacancy to zero, which is true in equilibrium, because of free entry into the market.

\section{B Equilibrium Definition}

A stationary equilibrium consists of

- Value functions for the employed, unemployed and the firm value.

- Free entry drives profits for newly posted vacancies to zero: $V^{I}=0$. 
- Wages solve

$$
\max _{w}:\left\{\alpha \log \left(V_{x}^{E}-V_{x, u_{1}}^{U}\right)+(1-\alpha) \log \left(V_{x}^{J}\right)\right\}
$$

where $\alpha$ is the bargaining power of workers.

- A policy function that is consistent with the value functions and that maps worker productivity, firm productivity, benefit entitlement, and the life cycle state into a decision, whether a match is formed or not.

- Stationary distributions of the employed and unemployed over worker productivities, employment states, life cycle states, benefit entitlement states and firm productivities.

\section{More on the empirics of on the job search}

\section{C.1 Measuring job to job employment flows}

In order to asses the efficiency of search on the job, it is crucial to accurately identify job to job transitions in the data. One of the biggest advantages in working with SIPP data is that workers are asked to report an employment status for each week of the reporting period separately. While a higher degree of time aggregation may mask intermittent unemployment spells, we can identify any unemployment spell lasting longer than one work week.

In a given month we count as employed someone who reports holding a job for the entire month. This definition includes paid as well as unpaid absences as result of vacations, illnesses or labor disputes. It does exclude, however, those who report having been on layoff for at least a week. There is no standard definition for job to job movements in empirical work. We therefore experiment with several different definitions. Our first measure is analogous to the definition in Fallick and Fleischman (2004) and equates job to job transitions with firm changes. We use a monthly employer identifier based on company names created by Stinson (2003). We refer to this definition by EE1. Given that a firm is a match in our model and given that employees may transit between jobs within a given firm, we find it useful to somewhat 
broaden the concept beyond employer id changes. For $E E 2$ we therefore follow Moscarini and Thomsson (2007) in identifying job to job movements by changes in the three digit occupational code. Moreover, we define $E E 3=E E 1 \cup E E 2$ and $E E 4=E E 1 \cap E E 2$.

Table 8: Different Definitions of EE Flow Rates

\begin{tabular}{lrrrr}
\hline \hline$E E 1$ & $E E 2$ & $E E 3$ & $E E 4$ & CPS \\
\hline 1.87 & 1.68 & 2.45 & 1.11 & 2.82 \\
\hline
\end{tabular}

Notes: The Table shows percentage probabilities job to job transitions based on SIPP data from end of 1992 to 1995. For reference we also quote monthly averages from Fallick and Fleischmann (2004) for the years 1994-1995. The different flow definitions can be found in the text.

Table 8 lists EE flow rates based on the different definitions. For comparison, we also report averages from monthly estimates for the years 1994 and 1995 taken from Fallick and Fleischman (2004) who use CPS data. Identifying EE movements by employer changes or changes in the occupational code alone yields roughly comparable flow sizes. However, only our broadest definition of job-to-job employment transitions comes close to the magnitude found using CPS. In order to ensure comparability of our results with studies based on CPS data and following the arguments made above, we calibrate our model baseline specification on the $2.45 \%$ based on definition EE3.

\section{C.2 Wages and On the Job Search}

We argue in the paper that the magnitude of job-to-job flows in itself is insufficient to evaluate the efficiency of on the job search. Instead, the question is how many of these job changes actually yield higher wages for the worker. In this section, we demonstrate that about a third of all job-to-job transitions result in lower nominal wages for the worker. Moreover, we demonstrate that this phenomenon is robust to all sorts of data stratifications. In our model, we interpret an important part of these movements as forced ones, which either mask the finding of a new job within notice period after having been layed-off or represent movements out of non- 
financial motives such as family reasons. We discuss some different interpretations of the phenomenon brought forward by the literature. As Postel-Vinay and Robin (2002) point out, these wage cuts might be the result of optimizing behavior if the worker expects a steeper wage trajectory at his new employer. As we demonstrate below, this hypothesis is not borne out by our data. Alternatively, one might blame measurement error in wages for the occurrence of the wage cuts. We demonstrate that augmenting our model by measurement error in wages does not change the results. Lastly, we put our results in perspective to some other contributions in the literature.

In the SIPP, respondents are asked, whether they are paid by the hour. If so, the reported hourly wage is recorded. Otherwise, we obtain hourly wages by dividing total monthly earnings by hours worked ${ }^{28}$. For the present purpose and all subsequent exercises, we drop any person/month observation for which we cannot determine an hourly wage. In addition, we drop observations without industry identifier, the selfemployed and EE movements which result in the individual holding more than one job after transiting ${ }^{29}$. Finally, we exclude the .75 percent most extreme observations from both ends of the wage growth distribution to get rid of outliers.

\section{C.2.1 Wage Gains from Employment Changes}

First, we consider the mean change in log wages after a job to job transition. Our results depend somewhat on whether we consider nominal or real wage changes. Of course, the worker should only care about real wages in making his decision. Meanwhile, an argument can be made that in the presence of some wage rigidity, the worker expects a real wage loss on his current job as well and therefore compares nominal wages. Table 9 shows mean nominal and real wage gains for our different definitions of job to job movements.

Wage gains after a job to job transition average only to about two percent. As shown in Table 9, this is because roughly thirty-four percent of these transitions

\footnotetext{
${ }^{28}$ For further details see the CEPR SIPP User Notes.

${ }^{29}$ An individual working two jobs simultaneously may have trouble correctly attributing hours worked to the different jobs. This could potentially add noise to the data.
} 
Table 9: Aggregate Changes in Wages after EE

\begin{tabular}{rrrrrrr}
\hline \hline & \multicolumn{3}{c}{ Nominal } & \multicolumn{3}{c}{ Real } \\
\hline Ave. change & Share loss & Ave. loss & Ave. change & Share loss & Ave. loss \\
\hline$E E 2$ & 0.0224 & 0.3444 & -0.2362 & 0.0199 & 0.5386 & -0.1534 \\
$E E 3$ & 0.0194 & 0.3738 & -0.2343 & 0.0171 & 0.5147 & -0.1725 \\
$E E 4$ & 0.0203 & 0.3390 & -0.2200 & 0.0179 & 0.5386 & -0.1409 \\
\hline
\end{tabular}

Notes: The Table shows statistics concerning wage changes after a job to job transition for real and nominal wages, respectively. The statistics under consideration are: The average change in log wages, the share of workers incurring a wage loss, and the average change in log wages, given that the observed change is a loss. We differentiate between four different measures of job to job transitions: $E E 1$ identifies a job to job transition, if a worker is employed at a different firm between two consecutive months. EE2 identifies a job to job transition, if the worker's 3 digit occupation code changed between two consecutive months. $E E 3=E E 1 \cup E E 2 . E E 4=E E 1 \cap E E 2$.

actually yield nominal wage losses. The figure increases to about fifty-two percent when considering real wages. Wage losses are not just frequent, they are also sizable. Conditional upon taking a cut after an EE movement, losses average to twenty-three percent for nominal and seventeen percent for real wages. Reassuringly, these figures are largely invariant to which definition we use. From now on, all statistics reported will therefore be based on EE3 only.

We also stratify our sample by different observable characteristics to show that the phenomenon we just described is not driven by a specific population sub group, but is a key characteristic of the entire labor market. The results are summarized in Table 10 .

We first split our sample into different years. The willingness of workers to accept a wage reduction upon transition might depend on the aggregate state of the economy. In the years 1993 to 1995, the time of our sample, the US economy was gradually moving out of the post-Gulf War I recession and unemployment was steadily falling throughout the sample period. Still, as indicated in the first panel of Table 10, there is now discernible time trend in the data. By 1995, unemployment had reached a historic low but workers still accepted a wage cut when making an EE movement about one third of the time. 
Table 10: Share of Wage Cuts After EE Movement in Different Subsamples

\begin{tabular}{|c|c|c|c|c|c|}
\hline & & Nominal & & Real & \\
\hline Stratify by: & & Share loss & Nr. of Obs. & Share loss & Nr. of Obs. \\
\hline \multicolumn{6}{|l|}{ Year } \\
\hline & 1993 & 0.3301 & 4649 & 0.5468 & 4650 \\
\hline & 1994 & 0.3299 & 3892 & 0.5267 & 3889 \\
\hline & 1995 & 0.3638 & 2959 & 0.5431 & 2959 \\
\hline \multicolumn{6}{|l|}{ Sex } \\
\hline & Male & 0.3367 & 6351 & 0.5335 & 6347 \\
\hline & Female & 0.3421 & 5176 & 0.5449 & 5178 \\
\hline \multicolumn{6}{|l|}{ Age } \\
\hline & $23-30$ & 0.3483 & 3659 & 0.5183 & 3658 \\
\hline & $31-50$ & 0.3368 & 6470 & 0.5419 & 6468 \\
\hline & $51-65$ & 0.3230 & 1398 & 0.5819 & 1399 \\
\hline \multicolumn{6}{|l|}{ Industry } \\
\hline & Agriculture & 0.3999 & 119 & 0.5719 & 119 \\
\hline & Manufacturing & 0.3173 & 4274 & 0.5241 & 4271 \\
\hline & Trade & 0.3550 & 3083 & 0.5434 & 3080 \\
\hline & Services & 0.3687 & 1287 & 0.5971 & 1287 \\
\hline & Government & 0.3379 & 2767 & 0.5259 & 2768 \\
\hline \multicolumn{6}{|l|}{ Income } \\
\hline & Lowest $25 \%$ & 0.2316 & 3125 & 0.4191 & 2958 \\
\hline & $25-75 \%$ & 0.3514 & 5567 & 0.5541 & 5716 \\
\hline & Top $25 \%$ & 0.4428 & 2835 & 0.6409 & 2815 \\
\hline
\end{tabular}

Notes: The Table shows the share of workers incurring a wage cut after a job to job movement, given different ways of splitting our sample. The column "Nr. of Obs." shows the number of measured job to job movements in the specific sub sample. Due to slightly different outlier identifications, this number does not need to match exactly between the cases of nominal and real wages.

Women are known to have less stable work relationships than men and might therefore be responsible for an overproportional share of loss making employment to employment transitions. Nonetheless, in the data both sexes have an equal probability of experiencing a wage cut after moving. The same holds for stratifications by age groups. Young workers have a looser attachment to the labor market and may initially experiment with different career paths or search for jobs with higher 
non-monetary benefits. But none of these phenomena cause the youngest age group to experience markedly more EE transitions with wage losses.

We try out two more relevant data subsets. The first concerns the industry the worker moves to. Some industries may offer substantial non-monetary benefits compared to others. Of course, this exercise is not only subject to selection issues, it is also well-known that wages show industry differentials. In consequence, we should be expecting to identify industry pairs where wages fall in expectations when moving from one industry to the other. In order to have sufficiently many observations for all subsamples, we group industries into four broad sectors using their three digit industry codes: Agriculture, Manufacturing, Trade, Private Services, and Government. There are notable differences between sectors. Still, the share of workers incurring a wage cut after a job to job transition never falls below 31.73 percent.

Lastly, we stratify our sample by earnings. We split the main sample into its lowest and highest quartile and the observations in between. Again, there is a selec-

tion issue because high wage earners are more likely to incur a loss when they are forced to look for alternative employment. In a simple employment lottery, where all workers sample wages from the same random distribution, the probability of incurring a wage loss is an increasing function of the current wage. Nonetheless, low wage earners are far from insulated to wage losses when switching jobs and even in the lowest quartile,twenty-three percent of all EE transitions result in nominal wage losses.

\section{C.2.2 Estimating the Measurement Error Process}

Te ensure that it is not measurement error that drives the fraction of agents accepting wage cuts upon job to job transitions, we simulate our model with measurement error. Recall that wages in the data are given by (2). To simulate our model with the same measurement error process, we require estimates of $\Theta(12)$ and $\sigma_{\iota}$. We obtain these by maximizing the sum of individual likelihoods of within job wage growth in the data. More specifically, we treat $\iota_{i, t}$ as unobserved state and obtain the individual likelihood for wage growth of individual i from the following state space representation 


$$
\rho_{i t+1}=\left[\begin{array}{llllllll}
1 & \\
\theta_{1}-1 \\
\theta_{2}-\theta_{1} \\
\theta_{3}-\theta_{2} \\
\theta_{4}-\theta_{3} \\
0
\end{array}\right.
$$

We impose one moment restrictions coming out from our calibration: $\beta_{1}^{2} \sigma_{\epsilon}^{2}=0.00032$. 
Table 11 shows the results from our estimation.

Table 11: Estimates for measurement error

\begin{tabular}{lr}
\hline \hline Parameter & Estimate \\
$\sigma_{\iota}$ & 0.0236 \\
$\theta_{1}$ & 0.066 \\
$\theta_{2}$ & -0.4426 \\
$\theta_{3}$ & 0.9846 \\
$\theta_{4}$ & 0.0779 \\
$\theta_{5}$ & 3.5932 \\
$\theta_{6}$ & 2.7587 \\
$\theta_{7}$ & 1.4039 \\
$\theta_{8}$ & 1.3519 \\
$\theta_{9}$ & 1.2144 \\
$\theta_{10}$ & -0.1461 \\
$\theta_{11}$ & -0.0096 \\
$\theta_{12}$ & 0.4869 \\
\hline \hline
\end{tabular}

Notes: The Table shows the estimation results for the measurement error process.

\section{Numerical Algorithm}

The numerical algorithm consists of three nested loops and a simulation afterwards. Codes are available from the authors' webpages.

- We begin the algorithm by guessing a labor market tightness $\theta$.

- Next, we guess the wage function over the states for the worker and discretize the workers' $\log$ productivity by 1500 grid points. We find 15 to be a non binding upper bound. The distribution of log firm productivities is discretized into 50 equi-likely grid points. The third dimension of the wage function are the two life cycle states.

- Given the initial guesses, we can start the inner loop, which calculates the value functions using value function iteration. Expectations regarding next pe- 
riod's idiosyncratic productivity are calculated using Gaussian quadrature with 10 nodes for evaluating the productivity innovations and spline interpolation between productivity grid points.

- Taking the value functions of the workers we start the middle loop that updates the wage function. We compute the value of the firm by Nash-Bargaining: $V_{x}^{J}(s)=\frac{1-\alpha}{\alpha}\left(V_{x}^{E}(s)-V_{x}^{U}(s)\right)$. Again using Gaussian quadrature and spline interpolation gives us the expected value of the firm next period. Using this and the value functions of the workers allows us to compute the policy functions.

- Solving the value of the firm function for wages yields the implied wage schedule for each grid point $\left(w_{\text {computed }}\right)$. Wages are only determined by Nash-Bargaining in equilibrium. However, worker heterogeneity implies that in equilibrium there will be certain potential matches whose surplus is negative. In order to be able to compute meaningful values of employment at these firms we set wages equal productivity or, put differently, we set the firm value to zero. Afterwards, we update wages by $w_{\text {new }}=\rho w_{\text {initial }}+(1-\rho) w_{\text {computed }}$ until convergence. $\rho$ is the updating weight and we find 0.75 to work fine at the beginning and increase it to 0.9 towards convergence.

- The last loop computes the implied $\theta$ by setting the value of a vacancy to zero. We therefore need the stationary distributions of the employed and the unemployed. We compute these by distribution function iteration, using the policy functions. For the distribution function we use a finer grid for worker productivities of 5000 grid points. Using the results, we update $\theta$ until convergence.

- The last step is the simulation, using the policy functions and equilibrium job offer rates. We use linear inter and extrapolation on the worker and firm productivity $\operatorname{grid}^{30}$.

\footnotetext{
${ }^{30} \mathrm{We}$ opt for linear interpolation at this step, as it considerably decreases the computational burden and does not appear to alter the results compared to spline interpolation. Also, spline extrapolation is known to be unreliable.
} 